\title{
Molecular genetics in the National Health Service in Britain
}

\author{
RODNEY HARRIS, ROB ELLES, DAVID CRAUFURD, \\ ALAN DODGE, ADRIAN IVINSON, KATHY HODGKINSON, \\ ROGER MOUNTFORD, MARTIN SCHWARTZ, TOM STRACHAN, \\ AND ANDREW READ \\ From the Department of Medical Genetics, St Mary's Hospital, Manchester M13 0JH.
}

SUMmaRY A recent report from the Departments of Health draws attention to the value of DNA diagnosis for inherited diseases and the need for planning these services in the National Health Service. There is great potential for preventive medicine, but a major immediate benefit is the newfound ability to exclude the carrier state in many people at risk and to protect fetuses from abortion when, as in most cases, they are shown to be normal by DNA tests. However, the widespread application of these new techniques requires prior evaluation and general acceptance. This will only be obtained after public debate, education of professionals and the population, and the establishment of adequate non-directive genetic counselling services. Some of the points to be considered in setting up molecular genetics laboratories are described.

About 14000 infants with wholly or partly genetic disorders are born each year in Britain, and a very much larger number of men, women, and children are at risk of being carriers of these and of later onset genetic disorders. These disorders cause much chronic disability and early death, while the fear of handicap leads to the unnecessary abortion of normal fetuses. Less tangible consequences include life long anxiety and unnecessary childlessness among those who erroneously believe themselves to be at risk of genetic disease. Now, molecular genetic (DNA) techniques offer hope to many people by showing that they are not carriers or that their fetus is normal. In the minority where fetal abnormality is detected, early selective abortion during the first trimester avoids the birth of a child with handicap.

The range and scope is rapidly increasing and population screening is possible in some instances, as in the successful thalassaemia programme among Greek Cypriots. ${ }^{12}$ More speculatively, identifying those genetically at risk of cancer, coronary heart disease, diabetes, etc may eventually permit targetting of health education programmes and true prevention of these common diseases. ${ }^{3}$

In view of the potential human and economic benefits, we describe the establishment of a Regional

Received for publication 13 October 1988.

Revised version accepted for publication 5 December 1988.
Molecular Genetics Service hoping that this may be helpful to others planning such services.

\section{The North Western Regional Genetics Service}

This National Health Service region is large with 19 health districts including the conurbation of Greater Manchester and a total population in excess of 4 million with approximately 50000 births each year. The Regional Genetics Service was established in the 1960s and has always been closely associated with the University Department of Medical Genetics. The genetic 'team' includes academic staff, consultant clinical geneticists, and senior scientists who, with other scientific, medical, and nursing staff, provide the regional clinical, cytogenetic, molecular genetic, and tissue typing services. The team is multidisciplinary cooperating closely 'under one roof.

\section{Regional genetic register}

The genetic register was set up after the report of the Clinical Genetics Society in $1978 .{ }^{4}$ The aim is complete ascertainment of patients with the clinically most important dominant and $\mathrm{X}$ linked diseases and chromosomal translocations. Registration of at risk but currently healthy relatives (which is entirely voluntary) provides counselling, rapid access to new 
scientific developments (including molecular genetics), and most importantly it allows confidence to be built up and maintained with long term contact and support during reproductive crises and other problems. The genetic team links the obstetrician, ultrasonographer, family doctor, and laboratory during prenatal diagnosis and helps to rationalise the long term follow up of patients with chronic genetic disease who tend otherwise to attend many outpatient clinics in a haphazard manner. Outpatient services for Huntington's disease, Duchenne/Becker muscular dystrophies, and adult polycystic kidney disease are organised jointly with relevant clinical specialists through the genetic register, and other diseases will be added as resources allow.

Most DNA tests for inherited disease require a suitable pedigree structure and investigation of several members of a family before any meaningful interpretation for a single person can be obtained. People, especially unaffected relatives who may not previously have been aware of their family history, are particularly sensitive and anxious about genetic disease, so. informed explanations are necessary before blood or other samples are obtained. It is important that such family testing be performed in advance of a pregnancy because prenatal diagnosis is now usually performed very early (at eight to nine weeks) by chorion villus sampling (CVS). These requirements are most efficiently achieved by linking the Molecular Genetics Service to the regional genetic register.

\section{Setting up the Regional Molecular Genetics Laboratory}

\section{B A C K G ROU N D}

A DNA laboratory was originally established in 1983 on a North Western Regional Health Authority (NWRHA) locally organised research grant. Three years ago the Departments of Health asked St Mary's Hospital, Manchester, with the Institute of Child Health, London and the Institute of Medical Genetics, Cardiff to assess recombinant DNA technology in relation to clinical genetics within the NHS. The Health Service Research Unit at St Thomas's Hospital, London was commissioned by the Departments of Health to carry out an independent cost effectiveness evaluation of the work. However, the Departments of Health attach such importance to the Special Medical Development (SMD) in DNA that an interim report has been published, ${ }^{5}$ endorsing the concept of close integration of the molecular genetics laboratory, clinical services, and genetic register. The report concludes: "The effectiveness of services now introduced in the SMD centres testifies the soundness of arrangements made for their delivery. These arrangements therefore provide a basis from which more comprehensive services may evolve."

Following this report, the NWRHA established in St Mary's Hospital, Manchester a diagnostic laboratory and funded a core team of two laboratory posts. The Departments of Health subsequently awarded a second grant to explore possible automation and population screening using DNA methods.

\section{Range of work}

The service is concerned with inherited disease and 0 is not involved with microbiological, pathological, N or other diagnostic uses of gene probes for nonMendelian disorders. The molecular genetics service is cannot function alone: in addition to the related $\overrightarrow{0}$ clinical and cytogenetic services, it draws upon the 을 support of an active molecular research group funded by University, MRC, Wellcome, and other $\frac{D}{0}$ grants. Academic staff are currently responsible for the direction of both service and research and $\overrightarrow{0}$ provide the overall strategy. Successful research $\mathscr{o}_{0}$ projects include the mapping of the gene for vitamin D resistant rickets, ${ }^{6}$ gene mapping in the HLA region including congenital adrenal hyperplasia, ${ }^{78}$ and an extensive study of deletions in the Duchenne/Becker muscular dystrophy locus. ${ }^{9}$ This research has pro- $\frac{\mathcal{Q}}{\varnothing}$ duced results which are quickly incorporated into $\cong$ the service, most notably the improvement in $\overrightarrow{\overrightarrow{0}}$ prenatal diagnosis of Duchenne/Becker muscular 3 dystrophy using deletion mapping, and the early diagnosis of congenital adrenal hyperplasia in female fetuses, the latter allowing a trial of treatment in utero.

The aim is to provide equal access for all $\frac{0}{3}$ NWRHA residents. This is achieved by (1) a network of consultant genetic clinics, centrally and in $\mathrm{O}$ the districts, (2) the genetic register, and (3) medical staff, health visitors, and genetic associates who carry out many home visits each year all over the Region.

The service is available for all families in the $N$ Region with Duchenne and Becker muscular dystrophy, cystic fibrosis, and adult polycystic kidney 0 disease. A service is also offered to all families with $\mathrm{\omega}$ Huntington's disease, subject to a detailed counselling protocol (see below). A limited (research 6 based) diagnostic service is being developed for $\overparen{D}$ families with myotonic dystrophy, congenital adrenal $\stackrel{\mathscr{f}}{\rightarrow}$ hyperplasia, and a number of $\mathrm{X}$ linked diseases and $\underline{T}$ will shortly be extended to neurofibromatosis and the fragile $\mathrm{X}$ syndrome.

The haemoglobinopathies are referred to the $\stackrel{\mathbb{Q}}{\square}$ national centre in Oxford, and locally most cancer ${ }^{0}$ and leukaemia molecular work is at the Christie 
Hospital, Manchester, but with shared genetic counselling staff. Biochemical genetic disorders go to the Willink Biochemical Genetics Laboratory, Royal Manchester Children's Hospital.

The St Mary's Hospital, Manchester molecular genetics team has helped to establish specialised or research DNA laboratories in several other departments and this is regarded as a key feature of the work. Scientists have been trained from tissue typing, cytogenetics, biochemical genetics, immunology, atherosclerosis research, haematology, and rheumatology, and from other countries including Poland, Hungary, and Czechoslovakia. Traditionally, patients have also come to Manchester from adjoining parts of Merseyside and Northern Regions and the molecular genetics laboratory appears to be adopting to some extent a supraregional role.

\section{DNA banks}

As recommended by the Clinical Genetics Society report, ${ }^{10}$ every effort is made to obtain and store DNA from key members (generally affected or aged) before they die. This invaluable and frequently irreplaceable material may be essential for future prenatal and presymptomatic tests on relatives.

\section{Evolution of the service}

The applications of DNA technology for the diagnosis of genetic disease were very limited in 1983 when the laboratory was established. Apart from the haemoglobin disorders, the first disease to become amenable to DNA diagnosis was Duchenne muscular dystrophy. This was followed rapidly by many others, accompanied by a progressive and rapid improvement in the diagnostic effectiveness of available gene probes. All the diseases included in the NWRHA genetic register are now accessible to clinical diagnosis by some form of DNA probing, although at different stages of development in each of the diseases tackled.

The work load generated by our evaluation of the four diseases that we have studied most closely are summarised below.

\section{Results with diseases included on the genetic register}

\section{DUCHENNE/BECKER MUSCULAR DYSTROPHY}

The only markers available when the service began were at a large genetic distance $(15 \mathrm{cM})$ from the Duchenne muscular dystrophy (DMD)/Becker muscular dystrophy (BMD) locus with high recombination rates and therefore poor clinical reliability. The present situation is remarkably different and direct pre- and postnatal diagnosis is possible in the
$60 \%$ of affected males who have a deletion of part of the DMD/BMD locus detectable using genomic and cDNA probes. ${ }^{9}$ Although deletion diagnosis cannot yet be used for carrier detection among women in these families (because of the difficulty of measuring gene dosage), gene tracking studies combined with serum creatine kinase assay have removed much of the ambiguity; many female relatives now can be given either very high or very low risks with relatively few that are intermediate (table 1a, figure). A striking feature of this work compared with only one year ago is the rarity with which males who might be normal are aborted (table $1 \mathrm{~b}$ ). Of the 53 prenatal diagnoses performed, 10 males were predicted to be at low risk, 25 were females, and all of these pregnancies are continuing or have come to normal births. Eighteen of a total of 28 males have been aborted because of high risk or after fetal sexing. The work loads generated by the 161 Duchenne register families are shown in table 2. To date 224 reports of carrier detection modified by DNA studies and 53 reports on prenatal diagnosis have been issued and transmitted through a genetic counselling interview.

TABLE 1a Depending on pedigree structure, CK and DNA analysis clarifies carrier risk for many women in muscular dystrophy families.

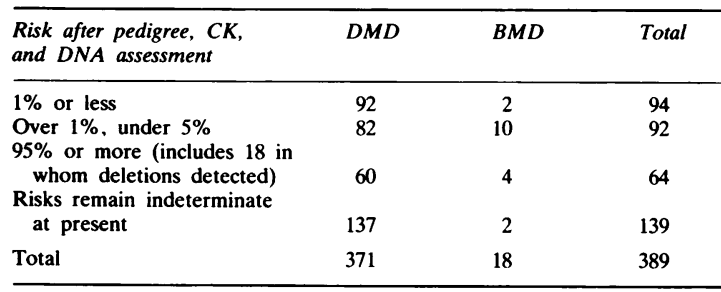

TABLE 1b Prenatal diagnosis of Duchenne muscular dystrophy using gene probes and chorionic villus sampling.

\begin{tabular}{ll}
\hline Totals & 28 \\
Male & 25 \\
Female & \\
Pregnancy outcome=continuing or normal (35) & 10 \\
DNA predicts low risk & 25 \\
Female & \\
Pregnancy outcome=termination (18) & 5 \\
Males with high risk & 4 \\
$\quad$ Dystrophin gene deletions & 6 \\
High risk chromosome & 2 \\
Male sexing only & 1 \\
$\quad$ Family uninformative, not worked up, tests not available & 6 \\
Family informative but not prepared to accept any risk & 2 \\
Family informative, results not obtainable & \\
\hline
\end{tabular}




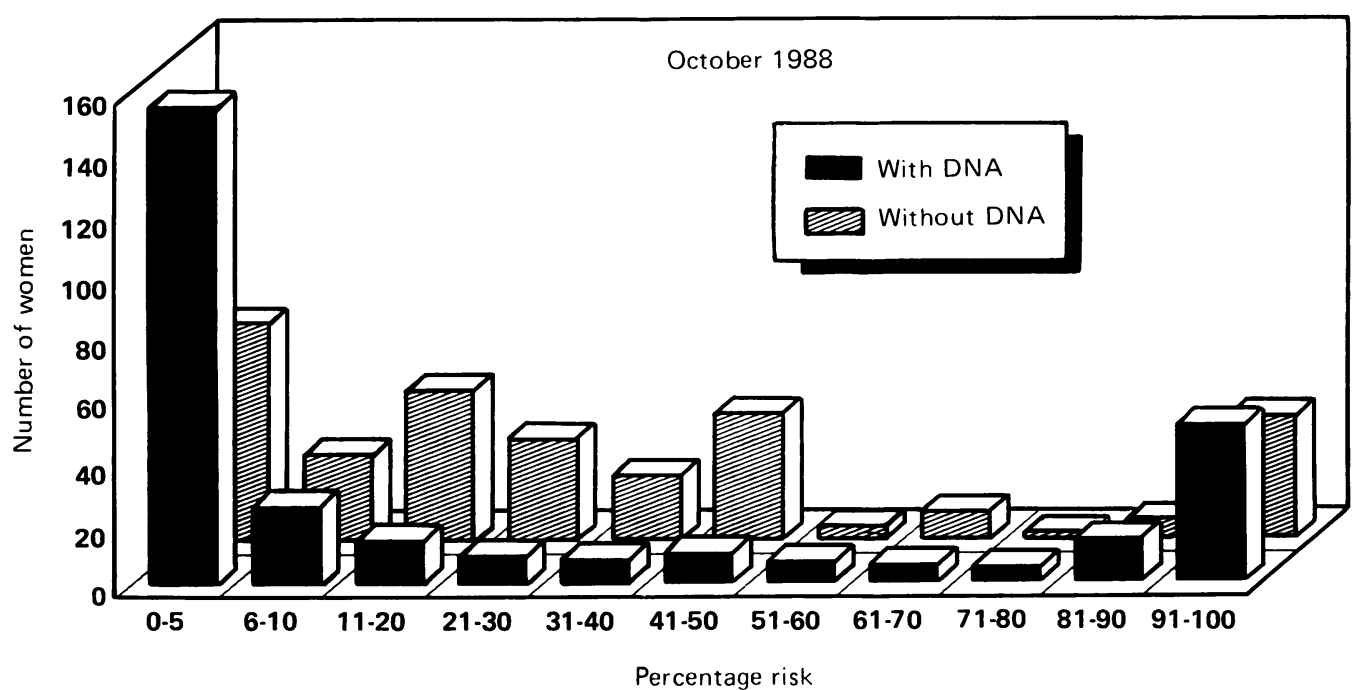

FIGURE Carrier detection in Duchenne/Becker muscular dystrophy families. Pedigree analysis and serum creatine kinase (CK) assay are frequently unable to assign female relatives to an unambiguously high or low risk category. The addition of gene tracking with DNA probes has already more than doubled the number of women in the lowest risk categories, while development work now in progress should remove nearly all women from uncertainty and provide accurate early prenatal diagnosis for the minority who are at high risk. The majority of fetuses are then found not to be affected and are saved from abortion.

TABLE 2 Work loads.

\begin{tabular}{lccc}
\hline & Samples processed & RFLP tests & Reports issued \\
\hline 1983 & 482 & N/A & N/A \\
1984 & 819 & 683 & N/A \\
1985 & 783 & 1432 & 4 \\
1986 & 1205 & 3066 & 124 \\
1987 & 1217 & 5700 & 244 \\
Total & 4506 & 10881 & 372 \\
& & & \\
Duchenne/Becker & 1882 & 6376 & 253 \\
Cystic fibrosis & 907 & 2864 & 110 \\
Huntington's disease & 652 & 1057 & 5 \\
Adult polycystic & & & \\
$\quad$ kidney disease & 303 & 382 & 4 \\
Other & 762 & 202 & 0 \\
Total & 4506 & 10881 & 372 \\
\hline
\end{tabular}

TABLE 3 Prenatal diagnosis of cystic fibrosis using gene probes and chorionic villus sampling. ' Coincident Down's syndrome.

\begin{tabular}{lccc}
\hline Prediction & Terminations & $\begin{array}{l}\text { Pregnancy } \\
\text { continuing/ } \\
\text { live births }\end{array}$ & Total \\
\hline Affected & 12 & 1 & 13 \\
Carrier & 0 & 37 & 37 \\
Unaffected & $1^{*}$ & 17 & 18 \\
50\% risk: & 2 & 1 & 3 \\
$\quad$ Carrier/affected & 0 & 3 & 3 \\
$\quad$ Carrier/unaffected & 0 & 59 & 74 \\
\hline
\end{tabular}

\section{Cystic fibrosis}

The first DNA markers linked to cystic fibrosis (CF) were published in October $1985^{11-13}$ and were $\rightleftharpoons$ quickly applied to prenatal diagnosis. ${ }^{14}$ Since April 1986 we have dealt with 74 (table 3 ) pregnancies, of which details have been published of the first $30 .{ }^{15} \widehat{\Xi}$ Currently 234 families are known to the NWRHA Genetic Centre. Informativeness testing has been undertaken in 178 families, of whom 137 are fully 8 informative. Studies are incomplete in 36 families $₹$ and five families remain only partially informative $ᄋ$ after testing with all the markers available to us. No $\rightarrow$ tests have been undertaken in 49 families where there is no clinical urgency, or the family structure is incomplete. Seven carrier risk evaluations and one $\Omega$ prenatal diagnosis have been completed using linkage $\tilde{O}$ disequilibrium between the $\mathrm{CF}$ locus and the markers XV2c, KM19, and CS7. ${ }^{16}$

\section{Huntington's disease}

Huntington's disease was the first disorder to be 0 included on the genetic register and we now have $\overline{0}$ information on 255 affected subjects in 198 families, $\stackrel{\mathbb{Q}}{\stackrel{\oplus}{\Omega}}$ with 1879 subjects at risk known to the register. At $\stackrel{\vec{Q}}{\mathbb{2}}$ first there were no gene probes available and we $\frac{\square}{\sigma}$ concentrated on obtaining and storing DNA from 
key persons in the families for future linkage phase determination. We have 731 such DNA samples. We also set out to identify NWRHA families with an appropriate structure for fetal exclusion or presymptomatic carrier detection.

Following the release of the G8 probe linked to Huntington's disease, ${ }^{17}$ we reviewed the ethical situation created by presymptomatic diagnosis of untreatable disease and identified the need for more information and detailed counselling. ${ }^{18} \mathrm{~A}$ three stage protocol of pretest counselling was designed with the help of the University Department of Psychiatry. After ethical committee approval this protocol is now being implemented, supported in part by the Wellcome Trust, and is synchronised with the laboratory procedures ensuring full counselling and minimum delay.

A total of 99 subjects has indicated an interest in presymptomatic testing and table 4 summarises progress. Nine subjects have an unfavourable family structure and no further investigations are possible with currently available probes. Eighty-three have completed at least the first of three counselling sessions and, of these, 31 are considering and 16 are actively preparing for tests, four have received favourable and four unfavourable test results, and three tests could not be completed because the gene markers were uninformative. Eight subjects decided against testing during counselling and another seven will probably do so. These proportions are unlikely to be representative as the persons were referred specifically for tests, were known to be keen, or were contacted by us because of a suitable family structure.

Five prenatal fetal exclusion tests for Huntington's disease have been performed. Two gave low risks and the pregnancies are continuing. Two gave a high risk and the pregnancies were terminated. One test gave a low risk but the pregnancy miscarried.

\section{Adult polycystic kidney disease (APKD)}

APKD is an autosomal dominant disease of delayed onset eventually affecting 1/1000 Caucasians and

TABLE 4 Presymptomatic testing for Huntington's disease: mainly self selected or otherwise unrepresentative cohort.

\begin{tabular}{lr}
\hline Excluded because family structure unsuitable & 9 \\
Gene probes uninformative & 3 \\
Subject decided against testing & 8 \\
Counselling in progress & 55 \\
Tests suggest Huntington's gene present & 4 \\
Tests suggest Huntington's gene not present & 4 \\
Total & 83 \\
\hline
\end{tabular}

is responsible for perhaps $10 \%$ of end stage renal failure. The genetic register approach is particularly useful in the management of APKD families. In cooperation with the Department of Renal Medicine, Manchester Royal Infirmary, relatives at high risk are recalled at 18 years of age and offered ultrasound screening. Those found to have cysts are then screened regularly for infections, hypertension, or evidence of impaired renal function, which are treated promptly. This is believed to delay end stage renal failure while organ transplantation is more likely to succeed if done before irreversible, generalised arterial disease has developed. Diagnosis before childbearing allows informed reproductive choice by the carrier who then has the option of prenatal diagnosis.

Greater precision in presymptomatic diagnosis became possible after the publication of a linked $3^{\prime} \alpha$ HVR (HyperVariable Region of the $\alpha$ globin locus) marker in September $1985 .{ }^{19}$ To date, 17 families have been tested and all have proved to be informative. Presymptomatic and prenatal diagnosis is available if requested, but counselling must emphasise the possibility of error attributable to genetic heterogeneity. ${ }^{20}$

Consumer acceptability is currently being studied in patients with APKD and their relatives as a vital part of the Departments of Health Special Medical Development evaluation. Our provisional data suggest that presymptomatic DNA diagnosis in adults is welcomed by the families as part of the well established screening and prevention programme. In contrast, there is little interest in prenatal diagnosis and of the 49 fertile subjects interviewed who were at $50 \%$ or greater risk after investigation, only nine $(18 \%)$ believed that they would request prenatal diagnosis for this disease. Where presymptomatic DNA testing is requested by adults in conjunction with ultrasound this presents no special ethical problem, simply offering greater precision. However, ethical problems do arise concerning informed consent when presymptomatic testing is requested for children by parents who are frequently, and understandably, seeking reassurance. Our current policy is to discuss these requests with paediatricians and parents, emphasising the need to be able to show an immediate advantage to the child, especially because of the possibility of errors in prediction owing to genetic heterogeneity. ${ }^{20}$

There are currently 120 families known to the register: 249 patients with APKD, 322 subjects at $50 \%$ risk, and 50 at a risk of $25 \%$. Thirty (presymtomatic) tests have been performed to date. No prenatal diagnoses have been performed although one family has requested testing for informativeness before future prenatal diagnosis. 


\section{DNA laboratory facilities}

EQUIPMENT

Since 1983 laboratory equipment worth more than $£ 150000$ has been accumulated from various sources including endowment funds, research grants, and university funds. The largest single capital sums have been provided from the Departments of Health Special Medical Development Grants referred to earlier. (An inventory of equipment requirements is available on request.)

ST A F F

At present the staffing level of the clinical laboratory service is set at 7.5 whole time equivalents, soon to be expanded to $11 \cdot 0$. Of these, two are funded by NWRHA, one by Central Manchester Health Authority, 3.5 by the second Departments of Health grant (two years), and the remainder are University or research funded.

RUNNING CosTS

The annual laboratory revenue budget (salaries and consumables) for the Regional Molecular Genetic Service is set by NWRHA at $£ 75000$. This does not include clinical costs, the Departments of Health evaluation funding, or research grants.

WORK LOADS

Table 2 summarises the total laboratory work load indicators for the period 1983 to 1987 including: number of samples processed, total restriction fragment length polymorphism (RFLP) tests performed, patient carrier risk determinations, and prenatal diagnoses reported.

\section{The future}

The rapidity of progress has been remarkable. Within only four years a small research project employing one scientist became, via the Departments of Health evaluation exercise, a regionally funded service for a defined population of more than 4 million. Comparable services involving closely knit clinical and laboratory teams have been set up in Cardiff, ${ }^{21}$ at the Institute of Child Health, London, and in a few other places. However, in the absence of guidelines, some regions have funded DNA laboratories without necessarily considering the clinical and counselling needs of the families or the acceptability of genetic screening. Guidelines are now emerging for service planning after the Departments of Health interim report ${ }^{5}$ on the Special Medical Development (SMD), which emphasises the need for multidisciplinary collaboration and well organised, efficient laboratories. Many details remain to be evaluated.
It is actually difficult to predict future developments except in rather general terms. The work loads will certainly increase because there are many inherited diseases that will become diagnosable by molecular methods, and there are exciting new techniques for DNA amplification involving polymerase chain reaction (PCR), ${ }^{22}$ which are already extending the range of applications of DNA techniques. Recent reports ${ }^{23}$ suggest that PCR will allow very rapid, even 'same day' reporting of prenatal diagnoses. Probes will probably become useful for the diagnoses of common chromosomal disorders. Population screening is already effective for the haemoglobin disorders with assistance from DNA techniques and this may become possible for cystic fibrosis, Down's syndrome, and the fragile $X$ syndrome. There are more distant prospects of predicting preventable cancer, coronary thrombosis, and diabetes.

At present, collecting and storing DNA from key relatives is the highest priority even in regions that have not yet established comprehensive molecular genetic services for Mendelian disorders. Future directions involving the use of PCR may permit the storage of such small quantities of blood as in Guthrie spots.

When such services are established the demand has two phases: there is a catching up phase during which the large backlog of families is cleared and a second less intensive phase resulting from the number of new cases expected, which is relatively small. For example, in Britain as a whole, there are only 350 cases each year of cystic fibrosis, or about 25 in each Health Service region of this, the commonest recessive disease. Screening for rarer disorders and the development of automated procedures will make cooperation between regions desirable.

During the early development stage, it is unnecessarily wasteful to establish more than a limited number of comprehensive laboratories, generally one per region. Family studies ('gene tracking') are labour intensive and require trained genetic register staff, while laboratory workers need continuing experience with each gene probe and a reasonably large number of cases to obtain reliable results. Much of the expensive equipment currently being evaluated for DNA extraction and amplification will $\varrho$ probably become rapidly obsolescent and DNA $\overparen{D}$ techniques in general will become simpler, cheaper, and less labour intensive. At that point DNA methods will probably be appropriate for most district general hospitals and in a wide variety of different laboratories.

It is not clear what the future relationship will be between specialised laboratories for inherited 
diseases and others now developing for the diagnosis of microbial disease, histopathology, chemical pathology, etc. It is unlikely that they will be particularly close after DNA techniques become routine in most laboratories because the organisation of genetic laboratories will probably remain rather different. This is because of the requirement for interpretation of the clinical implications for family members as well as patients and the long term follow up of families.

There is a pressing need for the evaluation of the acceptability of genetic screening as public awareness increases. ${ }^{24}$ Education, non-directive genetic counselling, informed consent, and confidentiality must all be considered as new services evolve and especially before population screening can be successfully initiated. We have found that one cannot assume that all, or even a majority, of persons at risk of genetic disorders will immediately request presymptomatic or prenatal diagnosis. Although it is unusual for a woman at risk for a Duchenne child to refuse investigations if she has had experience of the disease in a close relative, three-quarters of our patients with adult polycystic kidney disease (and those at $50 \%$ risk) currently believe that they would not want prenatal diagnosis. Perhaps this is because of the reassurance given by our regular screening and prompt treatment of a mainly adult onset disease. Anecdotal evidence also suggests that some parents of cystic fibrosis children are uncertain about prenatal diagnosis because of the optimism of paediatricians about advances in the clinical management of the disease. However, this cannot be the reason in the Huntington's register families who are still ambivalent about both presymptomatic and fetal exclusion tests. Undoubtedly acceptability will increase as the procedures become more familiar and if the direct diagnosis of most inherited diseases is possible.

We are grateful to Drs Dian Donnai, Helen Kingston, Maurice Super, Ann Watters, and other clinical and laboratory colleagues in Manchester, London, Cardiff, and elsewhere whose cooperation (and gene probes) have made this work possible. It is particularly pleasant to record the informed support of NHS general managers and of the Departments of Health.

\footnotetext{
References

1 Modell B, Petrou M, Ward RHT, et al. Effect of fetal diagnostic testing on birth-rate of thalassaemia major in Britain. Lancet 1984;ii: $1383-6$.

2 Old JM, Fitchers A. Heath C, et al. First trimester fetal
}

diagnosis for haemoglobinopathies: report on 200 cases. Lancet 1986;ii:763-6.

${ }^{3}$ Scott J. Molecular genetics of common disease. $\mathrm{Br}$ Med $\mathrm{J}$ 1987;295:769-71.

${ }^{4}$ Emery AEH, Brough C, Crawfurd M. Harper P, Harris R, Oakshott G. A report on genetic registers. J Med Genet 1978;15:435-42.

5 DHSS. Special medical development in clinical genetics. Interim report: Clinical effectiveness in the service context. Medical Division CDPNM, 1987.

${ }^{6}$ Read AP, Thakker RV, Davies KE, et al. Mapping of human X-linked hypophosphataemic rickets by multi-locus linkage analysis. Hum Genet 1986;73:267-70.

${ }^{7}$ Sinnott PJ, Dyer PA. Price DA, Harris R, Strachan T. 21-hydroxylase deficiency families with HLA identical affected and unaffected sibs. J Med Genet 1989;26:10-17.

${ }^{8}$ Strachan T, Sinnott PJ, Smeaton I, Dyer P. Harris R. Prenatal diagnosis of congenital adrenal hyperplasia. Lancet 1987:ii: 1272-3.

${ }^{9}$ Read AP, Mountford RC, Forrest SM, et al. Patterns of exon deletion in Duchenne and Becker muscular dystrophy. Hum Genet (in press).

10 Yates J, Malcolm S, Read AP. Guidelines for DNA banking. Report of a working party of the Clinical Genetics Society. J Med Genet 1989;26:245-50.

1 Tsui LC, Buchwald M, Barker D, et al. Cystic fibrosis defined by a genetically linked DNA marker. Science 1985;230:1054-7.

12 Wainwright B, Scambler PJ, Schmidke J, et al. Localisation of cystic fibrosis locus to human chromosome 7 cen-q22. Nature 1985;318:384-5.

${ }^{13}$ White R, Woodward S, Leppert M, et al. A closely linked genetic marker for cystic fibrosis. Nature 1985;318:382-4.

14 Farrall M, Law HY, Rodeck CH, et al. First trimester prenatal diagnosis of cystic fibrosis with linked DNA probes. Lancet 1986;i: $1402-5$.

15 Super M, Ivinson A, Schwartz M, et al. Clinical experience of prenatal diagnosis of cystic fibrosis by use of linked DNA probes. Lancet 1987;ii:782-4.

16 Ivinson AJ, Read AP, Harris R, et al. Testing for cystic fibrosis using allelic association. $J$ Med Genet (in press).

17 Gusella JF, Wexler NF, Conneally PM, et al. A polymorphic DNA marker genetically linked to Huntington's disease. Nature 1983;306:234-8.

${ }^{18}$ Craufurd DIO, Harris R. Ethics of testing for Huntington's chorea: the need for more information. Br Med J 1986;249-51.

19 Reeders ST, Breuning MH, Davies KE, et al. A highly polymorphic DNA marker linked to adult polycystic kidney disease on chromosome 16. Nature 1985;317:542-4.

20 Romeo G, Costar G, Catizone L, et al. A second genetic locus for autosomal dominant polycystic kidney disease. Lancet 1988 ; ii:8-11.

21 Meredith AL, Upadhyaya M, Harper PS. Molecular genetics in clinical practice: evolution of a DNA diagnostic service. $\mathrm{Br}$ Med J 1988;297:843-6.

22 Saiki RK, Scharf S, Faloona F, et al. Enzymatic amplification of $\beta$-globin genomic sequences and restriction site analysis for diagnosis of sickle cell anaemia. Science 1985;230:1350-4.

${ }^{23}$ Williams C, Williamson R, Coutelle C, Loeffler F, Smith J, Ivinson A. Same-day, first-trimester antenatal diagnosis for cystic fibrosis by gene amplification. Lancet 1988;ii:102-3.

${ }^{24}$ Harris R. Genetic counselling and the new genetics. Trends Genet 1988;4:52-6.

Correspondence to Professor R Harris, Department of Medical Genetics, St Mary's Hospital, Hathersage Road, Manchester M13 0JH. 